In October 1991, a completely new system of management was introduced, wherein multidisciplinary discussion and planning was delegated to "miniteams". Each mini-team consists of three or four staff members drawn from the pool of nursing staff, junior doctors, on-site school staff, occupational therapists etc. The mini-team is chosen by the clinical nurse manager in liaison with the consultant and senior registrar and an attempt is made to match the particular difficulties of the child with the expertise available. The team is chosen before the child is admitted and always includes the key nurse.

The mini-team meets as frequently as required, at short notice if necessary. The mini-team oversees the child's progress and is free to make day to day decisions asking for advice as appropriate. Also, each child has a full multidisciplinary review in the presence of the consultant, on average once every three weeks, and the mini-team is at this time expected to play a key part in immediate, short and long-term planning.

The reason for changing the system in this way included a hoped-for improvement in the working of the multidisciplinary team and in particular:

(a) improved access for all staff members for information regarding the children

(b) broader and more in-depth involvement by staff members in the management of children

(c) the safeguarding of time for discussion of the less challenging or threatening children

(d) to facilitate and prompt thoughtful crisis management between busy weekly meetings.

All staff involved in mini-teams were recently asked to take part in an anonymous survey of this new system. This showed overwhelmingly that the changes made were popular and have been felt to have led to better management of the children. In particular, it was felt that aims (a) $(d)$, previously outlined, had been attained.

Queen Mary's Hospital for Children

Philip Steadman STEPHEN W ARREN

Carshalton, Surrey

\section{Correct dose of imipramine in panic disorder}

Dear Sirs

In their article on the prescribing of antidepressants for anxiety disorders, Tyrer \& Hallstrom (Psychiatric Bulletin, February 1993, 17, 75-76) are incorrect in advising a dose of imipramine of 100-150 mgs daily in the treatment of panic disorder. Patients suffering from this form of anxiety disorder are intolerant of the side-effects. If imipramine is prescribed in the dose usual for the treatment of depressive disorder, most patients with panic disorder will be unable to tolerate it and an extremely effective treatment for the disorder will be lost. This fact was noted by those who first advocated the treatment (Zitrin et al, 1978). Many of us, who recognise the therapeutic potential of antidepressants in panic disorder, advocate commencement at low dose (Snaith, 1991). Fortunately, because of its use in paediatric practice for eneuresis, imipramine is available in a $10 \mathrm{mg}$ tablet. The better tolerance of this low dose regime, with gradual increase, has been demonstrated by Nutt \& Glue (1991). They found that once tolerance had been established, the dose may be increased up to $100 \mathrm{mg}$ daily. My experience is that frequently, when panic attacks occur in the absence of a concurrent depressive state, the attacks are effectively controlled by the $10 \mathrm{mg}$ daily dose alone.

Academic Unit of Psychiatry

Philip Snatth

St James's University Hospital

Leeds LS9 7TF

\section{References}

NUTT, D. J. \& GlUE, P. (1991) Imipramine in panic disorder. I. Clinical response and pharmological changes. Journal of Psychopharmacology, 5, 56-64.

SNaIth, P. (1991) Clinical Neurosis. Oxford: Oxford University Press.

Zrtrin, C. M., Klein, D. F. \& Woerner, M. G. (1978) Behavior therapy, supportive therapy, imipramine and phobias. Archives of General Psychiatry, 35, 307-316.

\section{Reply}

DEAR SIRS

Dr Snaith emphasises a point that was already indicated in our article, when we described the dosage range (wrongly typed as 'rate') as between 3 and $300 \mathrm{mg} / \mathrm{day}$. It is certainly a sound clinical strategy to begin with low dosage but we do not yet know whether some patients respond to a final dosage below that of a daily imipramine dose of $100-150 \mathrm{mg}$. Until we have studies which indicate significant imipramine/placebo differences in low dosage the recommendation for the higher dosage remains.

PETER TyRer

St Charles Hospital

London W10 6DZ

COSMO HALLSTRÖM

Charing Cross Hospital

London W6 8RF

Training in liaison psychiatry - the place of old age psychiatry?

DeAr Sirs

In their recommendations for training in liaison psychiatry (Psychiatric Bulletin, February 1993, 17, 